\title{
Language and Decoding Skills in Greek-English Primary School Bilingual Children: Effects of Language Dominance, Contextual Factors and Cross-Language Relationships Between the Heritage and the Majority Language
}

\author{
Theodora Papastefanou ${ }^{1}$, Daisy Powell ${ }^{2}$ and Theodoros Marinis ${ }^{1,3 *}$ \\ ${ }^{1}$ School of Psychology \& Clinical Language Sciences, University of Reading, Reading, United Kingdom, ${ }^{2}$ Institute of \\ Education, University of Reading, Reading, United Kingdom, ${ }^{3}$ Department of Linguistics, University of Konstanz, Konstanz, \\ Germany
}

OPEN ACCESS

Edited by:

Xinjie Chen

Stanford University, United States

Reviewed by:

Eva Commissaire,

Université de Strasbourg, France

Joana Acha

Basque Center on Cognition, Brain and Language, Spain

*Correspondence:

Theodoros Marinis

t.marinis@uni-konstanz.de

Specialty section: This article was submitted to

Language Sciences,

a section of the journal

Frontiers in Communication

Received: 15 May 2019 Accepted: 26 October 2019 Published: 14 November 2019

Citation:

Papastefanou T, Powell $D$ and Marinis T (2019) Language and Decoding Skills in Greek-English Primary School Bilingual Children: Effects of Language Dominance,

Contextual Factors and

Cross-Language Relationships

Between the Heritage and the Majority Language. Front. Commun. 4:65. doi: 10.3389/fcomm.2019.00065
Bilingual children are a heterogeneous population, as the amount of input and use of their languages may differ due to various factors, for example, the status of each language (majority, minority), which language is used in the school, and whether children are acquiring literacy in one or both languages. Their language ability depends to a large extent on the use of each language and on whether they each language at the same rate. The aim of the study was to investigate how primary school bilingual children in the UK perform on several domains of language and reading skills and how these relate to language dominance. Moreover, it addressed how this performance is affected by a range of contextual factors and whether there are cross-language relationships in the children's language and reading abilities. Forty Greek-English bilingual children in Year 1 and Year 3 were tested on vocabulary, phonological awareness, morphological awareness, morpho-syntax, and decoding in Greek and English. The results showed that as a group, the children were Greek dominant before the age of 4 but English dominant now and confirm that language dominance could change even before children enter school and affects language and literacy skills equally. A strong relationship between language use and performance was only in evidence in the minority language, which suggests that parental effort should be directed toward the minority language because schooling appears to level out differences in the majority language. There was no negative relationship between the use of the heritage language and children's language and reading performance in the majority language. In contrast, significant positive cross-language associations were revealed among vocabulary, phonological awareness, inflectional morphology and decoding skills. The practical implications of this study are that parents and teachers should be informed for the positive effects of heritage language use in and outside the home for the maintenance of the heritage language and for the development of the children's language and literacy skills.

Keywords: language dominance, language exposure, heritage language (HL), majority language, decoding, bilingualism, Greek, English 


\section{INTRODUCTION}

The number of bilingual children attending school in the UK has increased dramatically in the last years (National Association for Language Development in the Curriculum, www.naldic. org.uk). Bilingual children are a heterogeneous population, as some may speak two languages from birth, while others may begin learning a second language later in life. Moreover, the amount of input and use of their languages may differ due to various factors, for example, the status of each language (majority, minority), which language is used in the school, and whether children develop literacy skills in one or both languages. Their language ability depends to a large extent on a range of contextual factors, e.g., the use of each language (Silva-Corvalán and Treffers-Daller, 2015) and on whether they use each language at the same rate (Montrul, 2008, 2016). However, it is unclear if language dominance changes during the school years and whether it differs across different domains of oral language and reading skills. The present study aims to examine how primary school Greek-English bilingual children living in the UK who acquire Greek as a minority language and English as a majority language perform on several domains of language and reading skills and how these relate to language dominance. Moreover, it addresses how this performance is affected by a range of contextual factors. An additional area of interest was to find out whether there are cross-language relationships in the children's language and reading abilities. In what follows, we first introduce the Simple View of Reading (Gough and Tunmer, 1986) that provides a framework regarding the mechanisms underlying learning to read. Then we review research on linguistic and contextual factors that predict word-level reading abilities and research on cross-language relationships in language and reading abilities. The broad aim of this research is to understand more fully the benefits of bilingualism through investigating which language and contextual factors contribute to language and literacy development in all languages spoken by bilingual children and which domains of language and literacy show crosslanguage facilitation effects. This is why an important aspect of this research addresses cross-language relationships in reading development and oral language skills between the two languages spoken by bilingual children.

\section{Mechanisms Underlying Learning to Read - The Simple View of Reading}

The process of learning to read is one of the first main goals of primary education, therefore, reading was a particular area of interest for the current research. According to the Simple View of Reading (e.g., Gough and Tunmer, 1986), reading comprehension is the product of two dimensions: decoding and linguistic comprehension. While initially developed as a framework for reading development in the first language (L1), it has also been applied to reading development in bilingual children (Bonifacci and Tobia, 2017). Research has shown that bilingual children tend to have relatively strong decoding skills but can lag behind monolinguals in linguistic comprehension and thus also in reading comprehension
(Babayigit, 2014). In this study, we have focused on the two key dimensions: decoding and oral language skills that reflect linguistic comprehension.

An additional factor that should be taken into account when reading development is examined is the level of the orthographic consistency in the languages tested. Alphabetic languages differ in the consistency of the mappings between symbols and sounds. For example, Italian has a highly transparent orthography, where there is a one to one relationship between graphemes and phonemes. English, on the other hand, has an opaque orthography, with many inconsistent words with unpredictable spellings (e.g., yacht, through). Orthographic consistency may affect reading development across grades, for example the rate of acquisition has been shown to be faster in the relatively transparent vowelized Hebrew orthography than in English, although Hebrew was the minority language (Geva and Siegel, 2000). Geva and Siegel's (2000) study illustrated that the development of early reading skills in bilinguals may proceed faster in languages with transparent orthographies than in languages with opaque orthographies. This is in agreement with cross-linguistic comparisons of reading development in monolingual children which show different trajectories based on orthographic transparency (Seymour et al., 2003).

Taken together, research suggests that the development of early reading skills in monolinguals and bilinguals relies on the same mechanisms and set of skills, although the relative importance of the underlying components may differ as a function of language-specific properties (Geva and Wang, 2001). However, most existing research on bilinguals has only considered the children's reading development in their second language (L2) rather than both L1 and L2. Therefore, the previous literature has not yet adequately addressed the question of what is typical in bilingual reading development (Genesee, 2006; Marchman et al., 2010). In our study, we have examined the role of linguistic and contextual factors on word-level reading in both languages spoken by Greek-English bilingual children.

\section{Predictors of Word-Level Reading Skills: Phonological Awareness and Oral Language Skills}

Several studies have examined the acquisition of decoding skills across different languages (Ziegler et al., 2010; Caravolas et al., 2012; Gottardo et al., 2016). These studies have suggested that the development of decoding skills in alphabetic languages depends heavily on phonological processing abilities, such as phonological awareness, phonological memory, and rapid serial naming (Bradley and Bryant, 1983; Wagner et al., 1994). Phonological awareness is the ability to recognize and manipulate the relevant units in a particular spoken language (syllables, onset-rimes, phonemes). Phonological awareness is one of the best predictors of word reading skills in alphabetic languages even if the strength of the relationship differs according to orthographic consistency (Melby-Lervåg et al., 
2012). It has been found to be one of the most powerful predictors of word reading skills in languages with opaque orthographies, such as English, while its contribution in languages with transparent orthographies seems more limited (de Jong and van der Leij, 1999; Smythe et al., 2008).

Regarding the development of decoding skills in bilingual children, Verhoeven (2000) suggested that word reading in Dutch could be predicted by the same underlying processes in monolinguals and bilinguals, specifically blending (an aspect of phonological awareness) and letter knowledge. Geva et al. (2000) reported similar results for English, since phonological awareness and rapid naming were highly comparable in monolinguals and bilinguals, suggesting that monolinguals and bilinguals acquire basic literacy skills in a similar way (Chiappe et al., 2002).

While the role of phonological processing skills for early reading development is well-established, research has pinpointed several other predictors of word-level reading skills. For example, knowledge of print concepts and oral language have consistently been related to word-reading achievement across early grades in school (Scarborough, 1998). According to Kirby et al. (2008), vocabulary is related to decoding, since vocabulary knowledge accelerates the word recognition process by permitting the reader to access orthographic representations directly (holistically) without having to apply the grapheme-to-phoneme correspondence rules to each letter individually.

In line with the above, several further studies have investigated the relationship between expressive vocabulary and word reading performance in monolingual children (Chiappe et al., 2004; Ouellette, 2006). For instance, Nation and Snowling (2004) showed that expressive vocabulary, listening comprehension, and semantic skills predicted decoding both concurrently and longitudinally over and above non-verbal ability, phonological awareness, and non-word reading. In contrast, some other studies did not find a significant relationship between vocabulary and text reading accuracy or regular word reading in English (Muter et al., 2004; Ricketts et al., 2007). Moreover, some studies have shown that the impact of vocabulary on word reading only emerges at later stages and that word reading during initial stages is largely dependent on phonological skills (Ouellette and Beers, 2010). Importantly, several studies have found evidence that vocabulary might be less important for the development of word reading skills in languages with transparent orthographies (Ziegler and Goswami, 2005; Verhoeven et al., 2011; Suggate et al., 2014).

In terms of the contribution of vocabulary to word reading in bilinguals, similarly to studies on monolinguals, the few studies that have been carried out have shown mixed results, with some showing significant links between the two skills (Lindsey et al., 2003; Bellocchi et al., 2017) and others failing to find evidence for such a link (Durgunoglu et al., 1993; Geva et al., 2000). Given the contradictory findings from previous studies, the nature of the relationship between vocabulary and word reading remains unclear, particularly in bilingual children.

\section{Contextual Factors as Predictors of Oral Language Skills and Word-Level Reading Skills}

The development of oral language skills depends to a large extent on the amount and nature of language exposure (Pearson et al., 1997; De Houwer, 2009; Gathercole and Thomas, 2009; Hoff et al., 2012). Children exposed to and acquiring two languages have less exposure to each of the two languages compared to monolingual children of the same age, and as a result, they have often been shown to acquire each language at a slower rate than monolingual children of the same age, as they have insufficient exposure to English to achieve the same level of oral language skills as monolingual children (e.g., Hoff et al., 2012). However, differences may arise between the minority and majority language because dominance shifts to the majority language when children enter school and different domains of oral language skills (e.g., vocabulary, morphology, complex syntax) have been shown to be affected differently by contextual factors.

The relationship between the acquisition of vocabulary and the amount of bilingual exposure was investigated by Thordardottir (2011) in 5-year old simultaneous bilingual children acquiring French and English in Canada. The results revealed a strong relationship between the amount of exposure to either French or English and their performance in the correspondent language. Similar results were obtained by Duursma et al. (2007) who investigated the predictors of oral vocabulary in the children's minority language (Spanish) in the fifth grade in the United States. Apart from the role of Spanish support in the home, Duursma et al. (2007) revealed that support for Spanish in the classroom was necessary to promote the children's Spanish vocabulary. Similar findings in terms of vocabulary have been reported by Chondrogianni and Marinis (2011) who investigated how 6-to-9 year old sequential bilingual Turkish-English children acquire English as majority language in the UK. The children's L2 receptive vocabulary as well as complex syntax were predicted by the children's use of English in the home and the maternal proficiency in English. Their general grammatical abilities were predicted by the children's length of exposure and maternal proficiency in English, but there was no association between the acquisition of tense marking, English language use in the home and maternal proficiency in English, indicating that the acquisition of morphology may be less sensitive to contextual factors compared to the acquisition of vocabulary and complex syntax.

The relationship between contextual factors and word-level reading skills has received less attention compared to the relationship between contextual factors and oral language skills. Dolson (1985) investigated fifth- and sixth-grade Hispanic children from Spanish-speaking homes in California and showed that they performed better in Spanish reading abilities than children from homes where English was the dominant language. In a study of 10-year-old Italian-English speaking children living in Australia, the use of Italian in the home was associated with higher literacy outcomes in that language (Cahill, 1987). 
Thus, when the heritage/minority language is used more in the children's home, children show better reading skills.

Dickinson and Porche (2011) investigated whether there is a relation between bilingual children's language experiences, such as home language use, school language use, the quality and quantity of input that children receive before they start school, and their reading abilities at Grade 4. The results revealed that there was a significant relationship between the school environment experiences and vocabulary, decoding, and the children's comprehension ability at the sentence level. Similarly, Dickinson and Tabors (2001) explored both the language use in the home where English was spoken and the school environment of children at the age of 3, 4 , and 5 years in relation to reading development and showed that the children's home and school language use and input were correlated with their later reading development in English.

\section{Cross-Language Relationships in Reading Development and Oral Language Skills}

Previous research suggests that reading development in the heritage language can benefit reading development in the majority language (Cummins, 1976). For example, significant cross-language relationships have been demonstrated in reading skills (Durgunoglu et al., 1993; Chitiri and Willows, 1997) among Spanish-English speaking children in Canada. Importantly, none of the studies previously reviewed found a negative relationship between the usage of the heritage language in the home and children's language and literacy outcomes in the majority language. It seems that children receive sufficient exposure to the majority language at school to support the development of their word-level reading skills in the majority language. Moreover, there is evidence that reading achievement in the heritage language is positively associated with English reading outcomes, where English is the majority language (Cahill, 1987). Similarly, Dolson (1985) demonstrated that heritage/minority language use at home promotes reading performance of English as a majority language. These findings support (Cummins, 1979) interlinguistic dependence hypothesis that asserts that bilingual children are able to use their knowledge of their first language to support the acquisition of a second language. Finally, a systematic review by Melby-Lervåg and Lervåg (2011) examining the cross-linguistic transfer of oral language, phonological awareness, and decoding from L1 to L2 revealed the importance of both instructional language at school and closeness of the writing system for phonological awareness and decoding. For example, the relationship between L1 and L2 was higher when children were instructed in both languages. Similarly, the L1 and L2 decoding relationship was higher when both L1 and L2 were alphabetic than when L2 was alphabetic and L1 ideographic. An additional interesting finding of the study was the weak relationship between L1 and L2 oral language skills. This could be explained by the fact that children were from low socioeconomic background. Cummins $(1979,2004)$ demonstrated that the transfer between L1 and L2 oral language might be stronger in children from middle and high socioeconomic background, as they possibly have a more decontextualized L1 that benefits learning L2. In general, this systematic review highlighted the facilitative role that reading in an L1 can have in L2 learning, underscoring a key benefit of bilingualism.

Given the fact that bilingual children form a very heterogeneous population, where the amount of language input and exposure and biliteracy vary considerably, it is important to examine the development of the heritage and majority languages in relation with reading development in both languages in combination to contextual factors that lead to the heterogeneity of the population. Students who have developed strong reading comprehension strategies (e.g., predicting, clarifying, visualizing) and attitudes (love of reading) in a heritage language are highly likely to apply those same skills and attitudes to reading in the majority language. For students who arrive in U.K. schools with stronger oral proficiency (and literacy skills) in a language other than English, promoting heritage literacy development has the potential to affect positively English literacy development. However, there have only been a limited number of studies investigating the acquisition of oral language skills and reading in both the heritage and majority languages in combination with contextual and linguistic factors in bilingual children.

\section{THE PRESENT STUDY}

The aims of the study were to investigate how primary school Greek-English bilingual children living in the U.K. perform on several domains of language and reading skills and how a range of contextual and linguistic factors contribute to the development of the children's language and reading skills in the two languages spoken of the bilingual children. An additional area of interest was to address cross-language relationships between the two languages in the children's language and reading abilities and identify positive associations. To address these aims we administered an extensive battery of objective measures addressing language and reading abilities of the children in both languages, Greek and English. We predicted that dominance would shift from Greek to English when children enter primary school and that participants would perform better in English than Greek, reflecting increasing dominance to English through schooling. The dominant language may be stronger for skills that develop at school, such as decoding, and less strong for early acquired domains of language, such as phonology and vocabulary. To address the role of contextual factors, we used a parental questionnaire and collected information about the children's language exposure, parental level of education, and parental self-rated language proficiency and we investigated the associations between these factors and the objective measures of language and reading abilities. The hypothesis was that contextual factors would contribute positively to the children's performance on the objective measures of language and reading abilities. To address cross-language relationships between the two languages and how this may affect bilingual children's reading abilities we examined cross-language correlations between Greek and English expressive vocabulary, phonological awareness, 
morphological awareness, morpho-syntactic skills and decoding skills. We predicted cross-language correlations in phonological awareness and decoding skills and weaker correlations in oral language skills.

The research questions were:

1. Does children's performance on objective measures of language and literacy skills depend on age (Year 1 vs. 3 of primary school) and language (English vs. Greek tasks)?

2. What is the relationship between contextual factors and the children's performance on the objective measures of language and literacy, in each language?

3. Are there cross-language associations between Greek and English expressive vocabulary, phonological awareness, morphological awareness, morpho-syntactic skills and decoding?

\section{METHODOLOGY}

\section{Participants}

Forty typically developing Greek-English bilingual children were recruited from primary schools in the London, Reading and Oxford area: 20 from Year 1 (Mean age $=76.6$ months, $\mathrm{SD}=3.6,14$ boys and 6 girls) and 20 from Year 3 (Mean age $=100.4$ months, $\mathrm{SD}=3.4,9$ boys and 11 girls). All children attended an English mainstream primary school and a Greek supplementary school. Most children were born in the U.K., but some were born in Greece and moved to the UK at least 2 years before the commencement of the study. The children came mostly from families of average and above-average socioeconomic status. Moreover, none of them had any history of speech and/or language delay or impairment and their parents were not concerned about their language development.

The LITMUS-PABIQ questionnaire (Tuller, 2015) was provided to the participants' parents in order to obtain data in terms of the children's language history, quantity and quality of input, and use. The questionnaire includes the following sections: general information about the child, child's early history (e.g. language), current language skills, language used at home, languages spoken outside the home and information about the mother and the father (education). Parents had to demonstrate how often the child communicates in different languages, English and Greek, every day based on a scale from 0 to $4(0$-never; 1-rarely; 2-sometimes; 3-usually; 4-always). The data are summarized in Tables 1, 2.

To examine whether the children's language skills in Greek differed from their English skills, according to parent reports, we ran paired samples $t$-tests. Analyses revealed that before the age of 4 years, children had significantly more exposure to Greek than English $\left[t_{(39)}=2.72, p<0.05\right]$. The picture was reversed for the children's current use of Greek and English. The parents reported significantly lower current use of Greek in the home than English $\left[t_{(39)}=-2.554, p<0.05\right]$, as well as significantly lower use of Greek outside the home than English [ $\left.t_{(39)}=-13.74, p<0.001\right]$. They also reported that their children's current language skills in Greek were lower than in English [ $\left.t_{(39)}=-6.92, p<0.001\right]$. Mothers' self-rated language proficiency was significantly higher
TABLE 1 | Descriptive statistics of language exposure before 4 years, current skills, language use in the home and outside the home, mother and father's self-rated language proficiency in Greek and English.

\begin{tabular}{|c|c|c|c|c|c|}
\hline & & \multicolumn{2}{|c|}{ Greek } & \multicolumn{2}{|c|}{ English } \\
\hline & & $\begin{array}{c}\mathrm{Y1} \\
(N=20)\end{array}$ & $\begin{array}{c}\mathrm{Y3} \\
(N=20)\end{array}$ & $\begin{array}{c}\mathrm{Y1} \\
(N=20)\end{array}$ & $\begin{array}{c}\mathrm{Y3} \\
(\mathrm{N}=20)\end{array}$ \\
\hline Language & Mean & 2.40 & 2.45 & 1.95 & 1.80 \\
\hline \multirow{2}{*}{$\begin{array}{l}\text { exposure before } 4 \\
\text { years }(/ 4)\end{array}$} & $\mathrm{SD}$ & 0.598 & 0.76 & 0.605 & 0.768 \\
\hline & Min-Max & $1-3$ & $1-3$ & $1-3$ & $1-3$ \\
\hline \multirow[t]{3}{*}{ Current skills (/15) } & Mean & 9.90 & 11.75 & 12.55 & 14.55 \\
\hline & SD & 2.7 & 1.97 & 1.76 & 0.759 \\
\hline & Min-Max & $7-15$ & $8-15$ & $10-15$ & $13-15$ \\
\hline \multirow[t]{2}{*}{$\begin{array}{l}\text { Language use in } \\
\text { home (/20) }\end{array}$} & $\begin{array}{l}\text { Mean } \\
\text { SD }\end{array}$ & $\begin{array}{c}5.40 \\
1.875\end{array}$ & $\begin{array}{l}7.05 \\
1.61\end{array}$ & $\begin{array}{l}7.75 \\
3.09\end{array}$ & $\begin{array}{l}7.70 \\
2.43\end{array}$ \\
\hline & Min-Max & $3-9$ & $4-10$ & $0-11$ & $4-12$ \\
\hline \multirow[t]{2}{*}{$\begin{array}{l}\text { Language use } \\
\text { outside home (/18) }\end{array}$} & $\begin{array}{l}\text { Mean } \\
\text { SD }\end{array}$ & $\begin{array}{l}5.00 \\
2.00\end{array}$ & $\begin{array}{l}8.00 \\
1.52\end{array}$ & $\begin{array}{l}11.35 \\
1.137\end{array}$ & $\begin{array}{c}11.95 \\
1.64\end{array}$ \\
\hline & Min-Max & $2-9$ & $5-10$ & $10-14$ & $9-14$ \\
\hline \multirow{3}{*}{$\begin{array}{l}\text { Mother's self-rated } \\
\text { language } \\
\text { proficiency (/4) }\end{array}$} & Mean & 3.70 & 3.75 & 3.20 & 3.25 \\
\hline & SD & 0.657 & 0.444 & 0.696 & 0.786 \\
\hline & Min-Max & $2-4$ & $3-4$ & $2-4$ & $2-4$ \\
\hline \multirow{3}{*}{$\begin{array}{l}\text { Father's self-rated } \\
\text { language } \\
\text { proficiency (/4) }\end{array}$} & Mean & 3.30 & 3.65 & 3.55 & 3.60 \\
\hline & SD & 1.34 & 0.503 & 0.605 & 0.503 \\
\hline & Min-Max & $0-4$ & $1-4$ & $2-4$ & $3-4$ \\
\hline
\end{tabular}

All scores were derived from the PABIQ parent-report questionnaire.

TABLE 2 | Descriptive statistics Parental Educational Level in Years.

\begin{tabular}{|c|c|c|c|c|c|}
\hline & & \multicolumn{2}{|c|}{ Mother } & \multicolumn{2}{|c|}{ Father } \\
\hline & & $\begin{array}{c}\mathrm{Y1} \\
(N=20)\end{array}$ & $\begin{array}{c}\mathrm{Y3} \\
(N=20)\end{array}$ & $\begin{array}{c}\text { Y1 } \\
(N=20)\end{array}$ & $\begin{array}{c}\mathrm{Y3} \\
(N=20)\end{array}$ \\
\hline \multirow{3}{*}{$\begin{array}{l}\text { Educational level } \\
\text { in years }\end{array}$} & Mean & 17.8 & 17.9 & 18.3 & 17.7 \\
\hline & SD & 1.8 & 1.8 & 1.8 & 1.4 \\
\hline & Min-Max & $16-21$ & $16-21$ & $16-21$ & $16-21$ \\
\hline
\end{tabular}

All scores were derived from the PABIQ parent-report questionnaire.

in Greek than English $\left[t_{(39)}=2.9, p=0.007\right]$. However, fathers' self-rated language proficiency in Greek was not significantly different from English $\left[t_{(39)}=-0.448, p=0.656\right]$. In terms of the parental educational level, there was no significant difference between the educational level of mothers and fathers $\left[t_{(39)}=\right.$ $-0.374, p=0.711]$. These results indicate that as a group, the children were Greek dominant before the age of 4 but English dominant now. The final part of the first question addresses language dominance at the individual level.

To examine language dominance at the individual level on the basis of language use before age 4, we subtracted Greek Exposure before the child was 4 years old from English Exposure before the child was 4 years old. The same subtraction was carried out for current use of the two languages within the home and outside the home. The results showed that 21 of the 40 (52.5\%) children were Greek dominant before the age 4, but currently, 13 of the 40 children (32.5\%) were Greek dominant within the home 
and all children were English dominant outside the home. To examine language dominance on the basis of Current Language Skills, we subtracted the Greek score from the English score. Two participants from Year 1 had a negative score, which indicates that they were Greek dominant in terms of their current language skills. All other children were English dominant in terms of their current language skills.

\section{Materials}

The participants were assessed in both their languages in order to estimate their language and reading skills in both Greek and English. Standardized and non-standardized assessments as well as experimental tasks were used to measure the children's nonverbal abilities, vocabulary, phonological awareness, and reading decoding skills. A parental questionnaire was used to measure the children's language history. To be able to compare the children's performance in English and Greek, we included assessments that had parallel versions in the two languages. Full details of the tasks used are given below.

\section{Non-verbal IQ}

Raven's Colored Progressive Matrices Test (Raven et al., 2004) was used to measure the children's non-verbal abilities. The test was developed to measure general ability in children aged 4 to 11 years in educational and clinical settings. Test-retest reliability was reported as 0.88 for Progressive Matrices. The CPM consists of 36 perceptual and conceptual matching exercises that are divided into three sets of 12 items, whereby the items increase in difficulty within a given set. The raw score is the total number of correct items out of 36 .

\section{English Vocabulary}

Children's expressive vocabulary in English was measured with the Renfrew Word Finding Vocabulary Scale (Renfrew, 1995). The test was developed for use with children aged 3-8 years, and it consists of 50 black-and-white line drawings of objects. The raw score is the total number of correct items out of 50 . The Renfrew manual does not report the test-retest reliability.

\section{Greek Vocabulary}

To measure vocabulary in Greek, children were administered the Greek version of the Renfrew Word Finding Vocabulary Scale (Renfrew, 1995) which was developed by Vogindroukas et al. (2009). The test uses the same picture stimuli as the Renfrew in English with the exception of two items which were replaced with a similar item appropriate for the Greek culture (English: steeple/spire -> Greek: trulos "dome" and English: cuff -> Greek: blusa "pullover"). Moreover, the original line drawing for the item beehive/kipseli was replaced with a picture that depicts a typical beehive in Greece. The correct answers for three items were extended to include another commonly used alternative (kite: chartaetos/aetos, spanner: galliko klidi/kavuras and sling: narthikas/epidesmos). The raw score was the total number of correctly named items out of 50 . The test manual does not report the test-retest reliability.

\section{English Phonological Awareness}

The blending and elision tasks from the Comprehensive Test of Phonological Processing-Second Edition (Wagner et al., 2013) were used for English. The blending task requires the examinee to listen to a series of separate sounds and then put the sounds together to make a whole word. There were 20 test items. Testing was discontinued after three consecutive errors were made and a participant's score was the number of correct items. The elision task includes 3 practice items and 24 test items. Four test items required the participant to say the word without saying one of the syllables, and the remaining 20 items required the participant to say a word without saying a designated sound in the word. A participant's score was the number of correct items. Preliminary analysis revealed a correlation between blending and elision $(r$ $=0.723, p<0.01$ ), so to reduce the number of variables, we transformed these variables into composite scores. A composite score for blending and elision was calculated by calculating percentage correct for each task and using the mean of the two tasks ${ }^{1}$. Cronbach's alpha on the composite score had high reliability, Cronbach's a $=0.82$.

\section{Greek Phonological Awareness}

For blending in Greek we developed a task similar to the one from the CTOPP- 2 using the same testing procedure. Participants listened to the sounds of a word separately and had to put them together to create the word, e.g., i-p-n-o-s (ú $\pi$ vos $=$ nap), a-r-i-th-m-'o-s ( $\alpha \rho \imath \theta \mu$ ó $\zeta=$ number). The task included five practice items that asked participants to put together two syllables to make a word. Five of the test items required the participant to put an onset and a rime together to make a word, and the remaining twenty-one items require the participant to put individual sounds together to make a word. For elision in Greek we used the Greek adaptation of the CTOPP-2 by Georgiou et al. (2008). The task includes three practice items and 29 test items: four test items are compound words and the participant has to say the word without saying the constituent compound, e.g., /mpenovgaino/ ( $\mu \pi \alpha \iota \nu o \beta \gamma \alpha \iota \nu \omega=$ enter and exit the house) without /vgeno/ is /beno/ $(\mu \pi \alpha i v \omega=$ enter); four test items ask the participant to say a word without saying one syllable (e.g., /lemoni/ ( $\lambda \varepsilon \mu$ óv $\iota=$ lemon) without /le/ is /moni/ ( $\mu$ óvn); the remaining 21 items require from the participant to say a word without saying a phoneme in the word. The position of the removed phoneme varies across the 21 items. Based on preliminary strong correlations between blending and elision $(r=0.775, p<0.01)$, we transformed these variables into composites scores that had high reliability, Cronbach's $\mathrm{a}=0.76$.

\section{English Inflectional Morphological Awareness}

Two experimental tasks were developed in order to measure morphological awareness in inflectional morphology. The first task was a sentence analogy task based on Pittas and Nunes (2014). It examined whether children can perceive a verb transformation from present tense to past tense and vice versa as well as to third person singular. This task includes 24 items. For example, Experimenter: Mary dresses quickly; Mary dressed

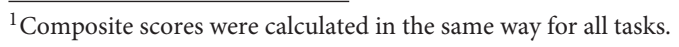


quickly. Experimenter: Mary kicks the ball; Child: Mary kicked the ball.

The second task was a sentence production task and was adapted from Rothou (2012). It measured the participants' ability to transform a verb from present tense to past tense and vice versa, from present progressive to past progressive and vice versa on the basis of the time adverb and includes 44 items. For example, Experimenter: Every day he cooks his lunch; Yesterday, he cooked his lunch. Experimenter: Every day, he kisses his mother. Experimenter: Yesterday, ...; Child: ... he kissed his mother. Both tasks included regular and irregular verbs in terms of the past tense transformation. Based on preliminary strong correlations between sentence analogy and sentence production tasks $(r=0.506, p<0.01)$, we transformed these variables into composites scores that had relatively high reliability, Cronbach's $\mathrm{a}=0.67$.

\section{Greek Inflectional Morphological Awareness}

The structure and administration of the Greek inflectional morphology tasks was the same as in the English versions of the tasks. The sentence analogy task was based on Pittas and Nunes (2014) and included 34 items. The task examines whether children can perceive a verb transformation from present tense to past tense and vice versa as well as to third person singular.

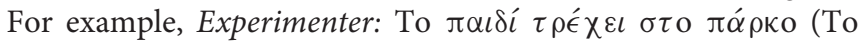
pedi trehi sto parko-The child runs in the park); To $\pi \alpha \iota \delta i$ $\dot{\varepsilon} \tau \rho \varepsilon \xi \varepsilon \sigma \tau$ о $\pi \dot{\alpha} \rho \kappa о$ (To pedi etrekse sto parko-The child run

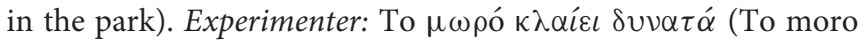
klei dunata-The baby cries loudly); Child: To $\mu \omega \rho$ ó $\varepsilon$ к $\kappa \alpha \psi \varepsilon$ $\delta$ ¿va $\tau \dot{\alpha}$ (To moro eklapse dunata-The baby cried loudly).

The sentence production task adapted from Rothou (2012) has 47 items and measured the participants' ability to transform a verb from present tense to past tense and vice versa, from present progressive to past progressive and vice versa based on the time adverb. For example, Experimenter: T $\omega \rho \alpha \alpha u \tau o ́ s$

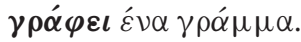

(Tora aftos grafi ena grama-Now he is writing a letter).;

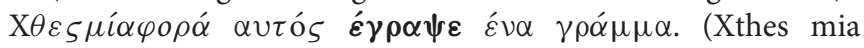
fora aftos egrapse ena grama-Yesterday he wrote a letter).

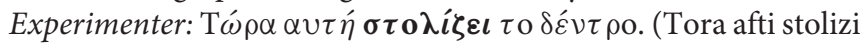
to dentro-Now she is decorating the tree). Experimenter: $X \theta \varepsilon \varsigma$,

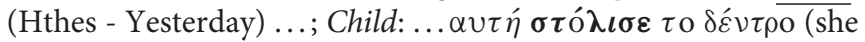
decorated the tree). Based on preliminary strong correlations between sentence analogy and sentence production tasks $(r=$ $0.672, p<0.01$ ), we transformed these variables into composites scores that had relatively high reliability, Cronbach's a $=0.76$.

\section{English Derivational Morphological Awareness}

Two tasks were designed in order to assess the children's morphological awareness of derivational morphology. The first task was a sentence analogy task adapted from Nunes et al. (1997) and Pittas and Nunes (2014). The participant was asked to provide a missing sentence based upon a pattern from the first sentence. The goal of this task was to investigate whether the participant was able to make the appropriate transformation from verb to noun; the derivational suffix chosen is /er/ and the task includes 10 items. For example, Experimenter: Bob wins: Bob is a winner; Experimenter: Bob writes: Child: Bob is a writer.

The second task was a production task with derivational words based on Casalis and Louis-Alexandre (2000) and Rothou (2012). The goal of this task was to assess whether the participant was familiar with the transformation from noun to adjective; the derivational suffixes which have been chosen are /y/, /ful/ and /ous/. The task includes 11 items. For example, Experimenter: The carpet has dirt.; The carpet is dirty Experimenter: Experimenter: This game has fun.; Child: This game is funny.

Based on preliminary strong correlations between sentence analogy and sentence production tasks $(r=0.514, p<0.01)$, we transformed these variables into composites scores that had quite low reliability, Cronbach's $\mathrm{a}=0.56$.

\section{Greek Derivational Morphological Awareness}

The structure and administration of the Greek derivational morphology tasks was the same as in the English versions of the tasks. The first task was a sentence analogy task adapted from Nunes et al. (1997) and Pittas and Nunes (2014). The participant was asked to provide a missing sentence based upon a pattern from the first sentence. The goal of this task was to investigate whether the participant was able to make the appropriate transformation from verb to noun; the derivational suffix chosen is the $/ \eta \mathrm{S} /$-/ish/ and includes 10 items. For example,

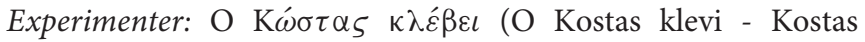

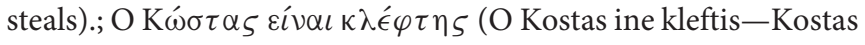
is a robber).; Experimenter: $\mathrm{O} \mathrm{K} \omega \tilde{\sigma} \tau \alpha \varsigma \times \tau \tau i \zeta \varepsilon l$ (O Kostas htizi-

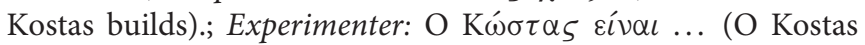
ine-Kostas is...).; Child: ... $\chi \tau i \sigma \tau \eta \varsigma$ (htistis-builder).

The second task was a production task with derivational words based on Casalis and Louis-Alexandre (2000) and Rothou (2012). The aim of this task was to assess whether the participant was familiar with the transformation from noun to adjective; the derivational suffixes which have been chosen are / $/ \mathrm{vo} / / / \mathrm{eno} /$,

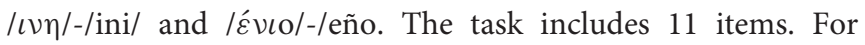

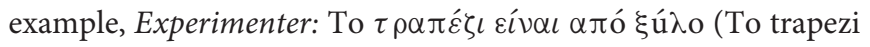
ine apo ksilo-The table is made from wood).; To $\tau \rho \alpha \pi \varepsilon \bar{\varepsilon} \zeta$

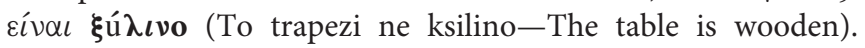

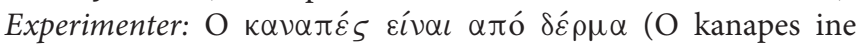
apo derma-The couch is made from leather).; Experimenter: $\mathrm{O}$

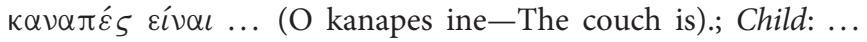
$\delta \varepsilon \rho \mu \alpha ́ \tau \iota \nu{ }^{\circ}$ (dermatinos -leather). Based on preliminary strong correlations between sentence analogy and sentence production tasks $(r=0.633, p<0.01)$, we transformed these variables into composites scores that had high reliability, Cronbach's $\mathrm{a}=0.81$.

\section{Sentence Repetition Tasks (S.R.T.) in English and Greek}

To measure children morpho-syntactic skills, a sentence repetition task was administered in both English and Greek. The tasks were used to assess different aspects of oral language skills, including knowledge and use of syntactic structures, ability to produce grammatically correct sentences, listening comprehension. 
Both the English and Greek Sentence Repetition Tasks were developed within the COST Action IS080419 (Marinis and Armon-Lotem, 2014). In this task, children have to listen to a series of sentences and are asked to repeat them verbatim. The English Sentence Repetition Task (English SRT) comprised 30 sentences that include a range of different grammatical structures. There were six sentences for each sentence type. The Greek Sentence Repetition Task (Greek SRT) was slightly longer and consisted of 32 sentences. There were eight different sentence types in the Greek SRT with four sentences each.

Both English and Greek had the same administration procedure. The sentences were pre-recorded by a native speaker of English and Greek, respectively, and were embedded into a PowerPoint presentation. The task was introduced as a game to the children named "The Treasure Hunt" featuring a bear named Teddy. Children were seated in front of a computer laptop and were given a set of headphones to prevent any noise disruptions. They were told that in order to follow Teddy on his treasure hunt, they had to listen carefully to the sentences and repeat exactly what they hear. Children's responses were voice-recorded and subsequently transcribed for further analyses. Children's responses were scored for overall accuracy, grammaticality and correct use of the target structure. Based on preliminary strong correlations between accuracy, grammaticality and structure in both Greek and English, we transformed these variables into composites scores. Greek accuracy was significantly correlated with Greek grammaticality $(r=0.592, p<0.01)$ and Greek structure $(r=0.596, p<0.01)$, and Greek grammaticality was significantly correlated with Greek structure $(r=0.718, p<$ 0.01). English accuracy was significantly correlated with English grammaticality $(r=0.884, p<0.01)$ and English structure $(r=$ $0.848, p<0.01)$, and English grammaticality was significantly correlated with English structure $(r=0.873, p<0.01)$. Both English and Greek versions had high reliability, Cronbach's alpha for the Greek task was 0.83, and for the English version was 0.95.

\section{English Decoding}

The Test of Word Reading Efficiency (Torgesen et al., 2012) was used to assess the participants' word-level reading skills in English. This test includes two subtests: The Sight Word Efficiency subtest assesses the number of real printed words that can be read accurately within $45 \mathrm{~s}$, and the Phonemic Decoding Efficiency subtest measures the number of pseudo-words that can be decoded accurately within $45 \mathrm{~s}$. The score was the number of words read correctly. Torgesen et al. (1999) reported test-retest reliability of 0.95 for ages 6-9 years. Based on preliminary strong correlations between word reading and pseudo-word reading $(r=0.548, p<0.01)$, we transformed these variables into composites scores that had relatively high reliability, Cronbach's $\mathrm{a}=0.69$.

\section{Greek Decoding}

For decoding in Greek we used the adaption of the TOWRE2 by Georgiou et al. (2012). It consists of 104 words beginning with one syllable words and ending with three syllable words. However, in Greek the words were relatively longer than in English. Georgiou et al. (2008) reported test-retest reliability of 0.96 for grade four. The score was the number of words read correctly. For the TOWRE-Phonemic Decoding Efficiency subtest, an 8 -item practice list was presented first, followed by a list of 63 pseudo-words in three columns (ordered in terms of difficulty). Children were asked to read the pseudo-words as quickly as possible. Based on preliminary strong correlations between word reading and pseudo-word reading $(r=0.712, p<$ 0.01 ), we transformed these variables into composites scores that had high reliability, Cronbach's a $=0.82$.

\section{Procedure}

Children were assessed individually in a quiet room in their schools or homes. Testing was divided into two sessions lasting roughly $45 \mathrm{~min}$ each. One session consisted of measuring the children's non-verbal IQ, English expressive vocabulary, phonological awareness, and decoding. In this session the participants' parents completed the LITMUS-PABIQ questionnaire. The other session consisted of the administration of the Greek language and literacy tasks (expressive vocabulary, phonological awareness and decoding). The order of the sessions as well as the order of the tests within each session were counterbalanced. Parental written consent was obtained prior to onset of the data collection.

\section{RESULTS}

\section{Comparison Between the Children's Performance on the Two Languages in the Two Schools Years}

The first research question addressed if there is a difference between the children's performance on objective measures of reading and reading-related skills in School Year 1 and 3 and between the Greek and English tasks.

Tables 3, 4 summarize children's performance in School Year 1 and 3 in expressive vocabulary, phonological awareness (blending and elision), morphological awareness, morpho-syntax and decoding tasks (word and pseudo-word reading) in the two languages.

To examine differences between the Year groups and between Greek and English, we entered the results (in percentages correct) into repeated-measures ANOVAs with School Year as the between participants factor and Language as the within participants factor, for each task separately. In all tasks, there was a significant main effect of School Year, favoring Year 3 as expected [expressive vocabulary: $F_{(1,38)}=24.02, p<0.05$, $\eta_{p}^{2}=0.387$; blending: $F_{(1,38)}=18.99, p<0.05, \eta_{p}^{2}=0.333$; elision: $F_{(1,38)}=51.37, p<0.05, \eta_{p}^{2}=0.575$; decoding (word reading) task: $F_{(1,38)}=21.14, p<0.001, \eta_{p}^{2}=0.357$; decoding (pseudo-word reading) task: $F_{(1,38)}=26.51, p<0.05, \eta_{p}^{2}=$ 0.411 ; inflectional morphology (analogy task): $F_{(1,38)}=6.11$, $p<0.05, \eta_{p}^{2}=0.138$; inflectional morphology (production task): $F_{(1,38)}=40.15, p<0.001, \eta_{p}^{2}=0.514$; derivational morphology (production task): $F_{(1,38)}=7.85, p=0.008, \eta_{p}^{2}$ $=0.171$; S.R.T.- accuracy: $F_{(1,38)}=34.16, p<0.001, \eta_{p}^{2}$ $=0.473$; S.R.T. - grammaticality: $F_{(1,38)}=50.72, p<0.001$, 
TABLE 3 | Descriptive statistics of the children's performance on the Greek and English expressive vocabulary, phonological awareness (blending, elision), decoding (real-words, pseudo-word) tasks (percentage correct).

\begin{tabular}{|c|c|c|c|c|c|}
\hline & & \multicolumn{2}{|c|}{ Greek } & \multicolumn{2}{|c|}{ English } \\
\hline & & $\begin{array}{c}Y 1 \\
(N=20)\end{array}$ & $\begin{array}{c}\mathrm{Y3} \\
(N=20)\end{array}$ & $\begin{array}{c}Y 1 \\
(N=20)\end{array}$ & $\begin{array}{c}\text { Y3 } \\
(N=20)\end{array}$ \\
\hline \multirow{3}{*}{$\begin{array}{l}\text { Expressive } \\
\text { vocabulary }\end{array}$} & Mean & 58.1 & 73.8 & 76.4 & 87.6 \\
\hline & SD & 8.5 & 12.7 & 9.3 & 9.95 \\
\hline & Min-Max & $42-70$ & 50-94 & $66-100$ & $70-100$ \\
\hline \multirow[t]{3}{*}{ Blending } & Mean & 65.3 & 80.5 & 80.5 & 92.3 \\
\hline & SD & 16.2 & 9.7 & 10.3 & 6.6 \\
\hline & Min-Max & 40-95 & $65-100$ & $65-100$ & $80-100$ \\
\hline \multirow[t]{3}{*}{ Elision } & Mean & 53.1 & 81.4 & 69.3 & 85.3 \\
\hline & SD & 18.5 & 13.2 & 11.3 & 8.2 \\
\hline & Min-Max & 20.7-93.1 & $51.7-100$ & 50-90 & $70-100$ \\
\hline \multirow[t]{2}{*}{$\begin{array}{l}\text { Real-word reading } \\
\text { (accuracy) }\end{array}$} & $\begin{array}{l}\text { Mean } \\
\text { SD }\end{array}$ & $\begin{array}{l}57.6 \\
21.5\end{array}$ & $\begin{array}{l}79.1 \\
16.4\end{array}$ & $\begin{array}{l}67.6 \\
13.3\end{array}$ & $\begin{array}{l}82.7 \\
7.96\end{array}$ \\
\hline & Min-Max & 25-93.2 & $38.6-100$ & $38.9-86.1$ & 58.3-92.6 \\
\hline \multirow[t]{2}{*}{$\begin{array}{l}\text { Pseudo-word } \\
\text { reading (accuracy) }\end{array}$} & $\begin{array}{l}\text { Mean } \\
\text { SD }\end{array}$ & $\begin{array}{l}48.3 \\
19.9\end{array}$ & $\begin{array}{l}75.4 \\
18.1\end{array}$ & $\begin{array}{l}67.9 \\
14.3\end{array}$ & $\begin{array}{l}84.6 \\
7.03\end{array}$ \\
\hline & Min-Max & $20.6-84.1$ & $30.2-103.2$ & 34.9-93.9 & $65.2-95.5$ \\
\hline
\end{tabular}

$\eta_{p}^{2}=0.572 ;$ S.R.T.- structure: $F_{(1,38)}=52.04, p<0.001$, $\left.\eta_{p}^{2}=0.578\right]$.

There was also a significant main effect of Language, favoring English [expressive vocabulary: $F_{(1,38)}=85.81, p<0.05, \eta_{p}^{2}$ $=0.693$; blending: $F_{(1,38)}=60.39, p<0.05, \eta_{p}{ }^{2}=0.614$; elision: $F_{(1,38)}=12.22, p<0.001, \eta_{p}^{2}=0.243$; inflectional morphology (analogy task): $F_{(1,38)}=104.22, p<0.001, \eta_{p}^{2}$ $=0.733$; inflectional morphology (production task): $F_{(1,38)}=$ 79.55, $p<0.001, \eta_{p}^{2}=0.677$; derivational morphology (analogy task): $F_{(1,38)}=5.21, p<0.05, \eta_{p}^{2}=0.121$; S.R.T. - accuracy: $F_{(1,38)}=107.001, p<0.001, \eta_{p}^{2}=0.738$; SRT_grammaticality: $F_{(1,38)}=48.95, p<0.001, \eta_{p}^{2}=0.563$; S.R.T. - -structure: $F_{(1,38)}=12.89, p<0.001, \eta_{p}^{2}=0.253$; decoding (word reading) task: $F_{(1,38)}=5.49, p=0.024, \eta_{p}^{2}=0.126$; decoding (pseudo-word reading) task: $F_{(1,38)}=52.427, p<0.05$, $\left.\eta_{p}^{2}=0.580\right]$.

Contrary to the prediction that language dominance may shift in these bilingual children between Year 1 and Year 3, there was no significant interaction between School Year and Language in vocabulary, phonological awareness, inflectional morphology and decoding tasks, indicating that the children had a higher score in Year 3 than in Year 1 and had a higher score in English compared to Greek in both School Year 1 and School Year 3 (expressive vocabulary: $F<1$, n.s.; blending: $F<1$, n.s.; inflectional morphology (analogy task): $F<1$, n.s.; inflectional morphology (production task): $F<1$, n.s.; derivational morphology (analogy task): $\mathrm{F}<1$, n.s.; SRT-accuracy: $F<1$, n.s.; SRT-structure: $F<1$, n.s.; decoding (word reading) task: $F<1$, n.s.
TABLE 4 | Descriptive statistics of the children's performance on the Greek and English morphological awareness and sentence repetition (SRT) tasks (percentage correct).

\begin{tabular}{|c|c|c|c|c|c|}
\hline & & \multicolumn{2}{|c|}{ Greek } & \multicolumn{2}{|c|}{ English } \\
\hline & & $\begin{array}{c}\text { Y1 } \\
(N=20)\end{array}$ & $\begin{array}{c}\mathrm{Y3} \\
(N=20)\end{array}$ & $\begin{array}{c}\text { Y1 } \\
(N=20)\end{array}$ & $\begin{array}{c}\text { Y3 } \\
(N=20)\end{array}$ \\
\hline \multirow[t]{2}{*}{$\begin{array}{l}\text { M.A. inflectional. } \\
\text { analogy }\end{array}$} & $\begin{array}{l}\text { Mean } \\
\text { SD }\end{array}$ & $\begin{array}{l}65.3 \\
16.2\end{array}$ & $\begin{array}{c}80.5 \\
9.7\end{array}$ & $\begin{array}{l}80.5 \\
10.3\end{array}$ & $\begin{array}{c}92.3 \\
6.6\end{array}$ \\
\hline & Min-Max & 40-95 & $65-100$ & $65-100$ & $80-100$ \\
\hline \multirow[t]{2}{*}{$\begin{array}{l}\text { M.A. inflectional } \\
\text { production }\end{array}$} & $\begin{array}{l}\text { Mean } \\
\text { SD }\end{array}$ & $\begin{array}{l}53.1 \\
18.5\end{array}$ & $\begin{array}{l}81.4 \\
13.2\end{array}$ & $\begin{array}{l}69.3 \\
11.3\end{array}$ & $\begin{array}{c}85.3 \\
8.2\end{array}$ \\
\hline & Min-Max & $20.7-93.1$ & $51.7-100$ & 50-90 & $70-100$ \\
\hline \multirow[t]{2}{*}{$\begin{array}{l}\text { M.A. derivational } \\
\text { analogy }\end{array}$} & $\begin{array}{l}\text { Mean } \\
\text { SD }\end{array}$ & $\begin{array}{l}57.6 \\
21.5\end{array}$ & $\begin{array}{l}79.1 \\
16.4\end{array}$ & $\begin{array}{l}67.6 \\
13.3\end{array}$ & $\begin{array}{l}82.7 \\
7.96\end{array}$ \\
\hline & Min-Max & 25-93.2 & $38.6-100$ & 38.9-86.1 & 58.3-92.6 \\
\hline \multirow[t]{2}{*}{$\begin{array}{l}\text { M.A. derivational } \\
\text { production }\end{array}$} & $\begin{array}{l}\text { Mean } \\
\text { SD }\end{array}$ & $\begin{array}{l}48.3 \\
19.9\end{array}$ & $\begin{array}{l}75.4 \\
18.1\end{array}$ & $\begin{array}{l}67.9 \\
14.3\end{array}$ & $\begin{array}{l}84.6 \\
7.03\end{array}$ \\
\hline & Min-Max & $20.6-84.1$ & $30.2-103.2$ & 34.9-93.9 & $65.2-95.5$ \\
\hline \multirow[t]{3}{*}{ S.R.T. accuracy } & Mean & 58.1 & 73.8 & 76.4 & 87.6 \\
\hline & $\mathrm{SD}$ & 8.5 & 12.7 & 9.3 & 9.95 \\
\hline & Min-Max & $42-70$ & 50-94 & $66-100$ & $70-100$ \\
\hline \multirow[t]{3}{*}{ S.R.T. grammar } & Mean & 65.3 & 80.5 & 80.5 & 92.3 \\
\hline & SD & 16.2 & 9.7 & 10.3 & 6.6 \\
\hline & Min-Max & 40-95 & $65-100$ & $65-100$ & $80-100$ \\
\hline \multirow[t]{3}{*}{ S.R.T. structure } & Mean & 53.1 & 81.4 & 69.3 & 85.3 \\
\hline & SD & 18.5 & 13.2 & 11.3 & 8.2 \\
\hline & Min-Max & 20.7-93.1 & $51.7-100$ & 50-90 & $70-100$ \\
\hline
\end{tabular}

There was, however, a significant interaction between School Year and Language in derivational morphology in the production task $\left[F_{(1,38)}=13.74, p<0.001, \eta_{p}^{2}=0.266\right]$. Children in Year 3 performed better $(M=61.82, S D=15.5)$ than children in Year 1 on English Derivational Morphology (production task) $(M=35.5, S D=12.1),\left[F_{(1,39)}=36.97, p<0.001\right]$, but there was no significant difference between children in Year 3 and Year 1 on Greek derivational morphology $\left[F_{(1,39)}=0.217, p\right.$ $=0.644]$. Moreover, children in Year 1 performed significantly better in the Greek $(M=48.64)$ than in the English derivational morphology task $(\mathrm{M}=35.5)\left[F_{(1,19)}=5.83, p<0.05, \eta_{p}^{2}=\right.$ $0.235]$. However, by Year 3, children performed better in the English $(\mathrm{M}=61.82)$ than in the Greek derivational morphology task $\left[\mathrm{M}=45.5 ; F_{(1,19)}=7.93, p<0.05, \eta_{p}^{2}=0.295\right]$.

A significant interaction between Language and School Year was also observed for the S.R.T.- grammaticality $\left[F_{(1,38)}=4.16\right.$, $\left.p<0.05, \eta_{p}^{2}=0.099\right]$. Children in Year 3 performed better $(M=$ $85.33, S D=10.6)$ than children in Year $1(M=66.5, S D=8.2)$ on the English S.R.T. $\left[F_{(1,38)}=34.10, p<0.001, \eta_{p}^{2}=0.479\right]$, and the same was true for the Greek S.R.T. (Year 3: $M=64.8, S D=$ 18.5; Year $1: M=34.8, S D=18.5 ; F_{(1,38)}=26.21, p=0.001, \eta_{p}^{2}=$ 0.408 . In both year groups children performed significantly better on the English compared to the Greek S.R.T. [Year 1, English: $M$ $=64, S D=6.5$; Year 1 , Greek $M=34.8, S D=18.5 ; F_{(1,38)}=$ 40.83, $p<0.001, \eta_{p}^{2}=0.518$; Year 3, English: $M=80.8, S D=11$; Year 3, Greek: $M=64.8, S D=18.5 ; F_{(1,38)}=12.28, p<0.001$, 
$\left.\eta_{p}^{2}=0.244\right]$. The interaction between Language and School Year is likely to result from the larger effect size in the Year $1(0.518)$ compared to Year 3 (0.244).

\section{Relationships Between the Objective Measures and Contextual Factors in Each Language Separately}

The second question addressed the relationships between parental report measures of children's language exposure and proficiency level, parental level of education, parental rating of their own language proficiency, and the objective measures of children's language and reading measures in Greek and English separately. Pearson's correlations were conducted, as shown in Tables 5, 6. To reduce the number of associations, from this point onwards we used the composite scores of the parental reports (parental level of education and parental self-rated language proficiency) and tasks measuring expressive vocabulary, phonological awareness (blending and elision), decoding (wordreading and pseudo-word reading), inflectional morphology (analogy and production), derivational morphology (analogy and production) and S.R.T. (accuracy, grammar and structure)see footnote 1 for an explanation of how composite scores were calculated.

The analysis revealed that overall, children's performance on the majority of the Greek tasks was significantly positively correlated with Greek language use outside the home. Specifically, for the results on the Greek tasks, expressive vocabulary was significantly positively correlated with language use in the home and outside the home. Inflectional morphology was significantly positively correlated with language use outside the home. The score of the S.R.T. task was significantly positively correlated with language use in the home and outside the home and parental self-rated proficiency. The score of the decoding task was significantly positively correlated with language use outside the home and parental educational level.

For the English language measures, the only significant positively relationship was between performance on the derivational morphology tasks and parental English proficiency level, as shown in Table 6.

No negative correlations were found between any of the factors and children's abilities in any of the two languages.

\section{Cross-Language Correlations Between Greek and English Language and Reading Skills}

An additional area of interest was to investigate whether there was evidence of cross-language associations in the children's language and reading skills. This was achieved through examining the cross-language correlations between Greek and English expressive vocabulary, phonological awareness (blending, elision), morphological awareness, morpho-syntactic skills and decoding (word reading and pseudo-word reading). Partial correlations were used to determine the relationship between Greek and English tasks controlling for age, as shown in Table 7.
As shown in Table 7, there were significant positive cross-language associations among vocabulary, phonological awareness, decoding and inflectional morphology. Specifically, Greek expressive vocabulary was significantly positive correlated with English expressive vocabulary. Greek phonological awareness was significantly positive correlated with English phonological awareness, Greek decoding, English decoding, Greek inflectional morphology and English inflectional morphology. Greek decoding was significantly positive correlated with English decoding. Greek inflectional morphology was significantly positive correlated with English inflectional morphology.

English expressive vocabulary was significantly positive correlated with Greek inflectional morphology. English phonological awareness was significantly positive correlated with Greek decoding, English decoding, Greek inflectional morphology and English inflectional morphology. English decoding was significantly positive correlated with Greek and English inflectional morphology.

\section{DISCUSSION}

The broad aim of this study was to understand more fully the benefits of bilingualism. Toward that aim, we investigated how Greek-English bilingual children who acquire Greek as a minority language and English as a majority language in the first and third year of primary school in the UK perform on several domains relating to both language and decoding dimensions of the Simple View of Reading (Gough and Tunmer, 1986), in both of the bilingual children's languages, Greek and English. Additionally, we addressed how this performance is affected by contextual factors, i.e., language use before the age of 4 years, current language use at home and outside the home, parental selfrated language proficiency and educational level. Participants' language dominance was measured taking into account the above biographical and environmental factors. This is one of the few studies to consider both linguistic and contextual factors in examining how language dominance affects diverse domains of oral and written language skills in the same population of children. An additional area of interest was to find out whether there are cross-language associations between the two languages in oral language and reading. The study focused on children who were all of similar age, socio-economic status, nonverbal abilities, and who have all been exposed to Greek and English, but no other languages. Where the children do differ is in their pattern of relative amount of exposure to the two languages which was documented in detail through a language history questionnaire. This allowed us to examine the association between the children's exposure to each language and their performance in each domain within each language.

\section{Language Dominance as Assessed Using Parental Reports and Objective Measures}

We first addressed language dominance using parental reports and objective measures. We investigated whether there was a difference between the children's level of exposure to Greek and 
TABLE 5 | Correlation matrix showing correlations between children's performance on objective measures and parent-questionnaire measures of language exposure before 4 years and language use in and outside home, mother and father's self-rated language proficiency and mother and father's educational level in Greek.

\begin{tabular}{|c|c|c|c|c|c|c|c|c|c|c|}
\hline & 1. & 2. & 3. & 4. & 5. & 6. & 7. & 8. & 9. & 10. \\
\hline \multicolumn{11}{|l|}{ 1. Expressive.Vocabulary.Gr } \\
\hline 2. P.A.Gr & $0.42^{\star \star}$ & & & & & & & & & \\
\hline 3. Inflectional.Morphology.Gr & $0.48^{\star \star}$ & $0.66^{\star \star}$ & & & & & & & & \\
\hline 4. Derivational.Morphology.Gr & 0 & 0.25 & 0.03 & & & & & & & \\
\hline 5. S.R.T.Gr & $0.46^{\star \star}$ & $0.34^{\star}$ & 0.22 & 0.08 & & & & & & \\
\hline 6. Decoding.Gr & $0.47^{\star \star}$ & $0.67^{\star \star}$ & $0.50^{\star \star}$ & 0.26 & 0.28 & & & & & \\
\hline 7. Greek Exposure before 4 years old & 0.10 & 0.02 & 0.11 & 0.16 & 0.08 & 0.10 & & & & \\
\hline 8. Language use in home & $0.41^{\star \star}$ & 0.10 & 0.11 & 0.01 & $0.31^{\star}$ & 0.09 & 0.12 & & & \\
\hline 9. Language use outside home & $0.54^{\star \star}$ & 0.31 & $0.32^{*}$ & 0.04 & $0.48^{\star \star}$ & $0.34^{\star \star}$ & 0.11 & $0.71^{\star *}$ & & \\
\hline 10. Parents.Edu.Level & 0 & 0.13 & 0.10 & 0.15 & 0.13 & $0.33^{* \star}$ & $0.37^{*}$ & 0.13 & 0.23 & \\
\hline 11. Parents.Prof.Level.Gr & 0.20 & 0.31 & 0.23 & 0 & $0.34^{*}$ & 0.21 & 0.23 & 0.18 & 0.27 & 0.14 \\
\hline
\end{tabular}

${ }^{\star *}$ Correlation is significant at the 0.01 level (2-tailed).

${ }^{*}$ Correlation is significant at the 0.05 level (2-tailed).

TABLE 6 | Correlation matrix for children's performance on objective measures and language exposure before 4 years and language use in and outside home, mother and father's self-rated language proficiency and mother and father's educational level in English.

\begin{tabular}{|c|c|c|c|c|c|c|c|c|c|c|}
\hline & 1. & 2. & 3. & 4. & 5. & 6. & 7. & 8. & 9. & 10. \\
\hline \multicolumn{11}{|l|}{ 1. Expressive.Vocabulary.Eng } \\
\hline 2. P.A.Eng & $0.52^{\star \star}$ & & & & & & & & & \\
\hline 3. Inflectional.Morphology.Eng & $0.65^{\star \star}$ & $0.75^{\star \star}$ & & & & & & & & \\
\hline 4. Derivational.Morphology.Eng & $0.43^{\star *}$ & $0.33^{\star \star}$ & $0.38^{\star *}$ & & & & & & & \\
\hline 5. S.R.T.Eng & $0.38^{\star \star}$ & 0.05 & $0.30^{\star \star}$ & $0.33^{\star \star}$ & & & & & & \\
\hline 6. Decoding.Eng & $0.72^{\star *}$ & $0.75^{\star \star}$ & $0.77^{\star \star}$ & $0.53^{\star \star}$ & $0.37^{\star \star}$ & & & & & \\
\hline 7. English Exposure before 4 years old & 0 & 0.19 & 0.05 & 0.18 & 0.06 & 0.19 & & & & \\
\hline 8. Language use in home & 0.20 & 0.07 & 0.11 & 0.13 & 0.13 & 0.08 & $0.40^{\star \star}$ & & & \\
\hline 9. Language use outside home & 0.20 & 0.19 & 0.22 & 0.05 & 0.17 & 0.16 & 0.27 & $0.53^{\star \star}$ & & \\
\hline 10. Parents.Edu.Level & 0 & 0.24 & 0.06 & 0.16 & 0.01 & 0.25 & $0.46^{\star \star}$ & 0.31 & 0.19 & \\
\hline 11. Parents.Prof.Level.Eng & 0.30 & 0.14 & 0.07 & $0.34^{\star}$ & 0.19 & 0.06 & 0.06 & 0.02 & 0.01 & 0.16 \\
\hline
\end{tabular}

${ }^{\star *}$ Correlation is significant at the 0.01 level (2-tailed).

${ }^{*}$ Correlation is significant at the 0.05 level (2-tailed).

English before the age of 4 years, their current language skills (at the time of testing, when children were in Year 1 or Year 3 of primary school) in the two languages, and their current language use of the two languages in the home and outside the home.

Previous research has shown that bilingual children have different abilities in their two languages, which is often linked with one language being more dominant (e.g., Thordardottir et al., 2006). Moreover, bilinguals' language ability is associated with the amount of input, use and schooling (e.g., Montrul, 2008; Silva-Corvalán and Treffers-Daller, 2015). In the present study, the children grew up in the UK with Greek as a minority language and English as a majority language and they attended English mainstream schools. As a result, English was expected to be the children's dominant language outside the home.

The language history questionnaire included information about the children's exposure to both Greek and English in the home and outside the home both before they had started school (before the age of 4 years) and also at the time this study was conducted, as well as about the parental perception of their children's current language skills. This enabled us to address the children's relative language dominance on the basis of exposure as well as subjective proficiency. We were also able to measure language dominance based on the children's performance on objective measures of their proficiency in the two languages.

According to the questionnaire, the children were Greek dominant before the age of 4 , but by the time of the study, when they were in either Year 1 or Year 3, they were English dominant. In terms of dominance inside and outside the home, we found that currently only $32.5 \%$ of the participants were Greek dominant within the home, whereas all children were English dominant outside the home.

The results on dominance based on language exposure were in line with the results on dominance based on the parental perception of their children's current language skills: the parents indicated that the majority of children had better language skills in English compared to Greek, and were thus English dominant. This finding is also in line with the children's performance on the objective tasks measuring language and reading skills, as they 
TABLE 7 | Partial-correlation matrix for children's performance on expressive vocabulary, phonological awareness, morphological awareness, morpho-syntactic skills, decoding in Greek and English controlling for age.

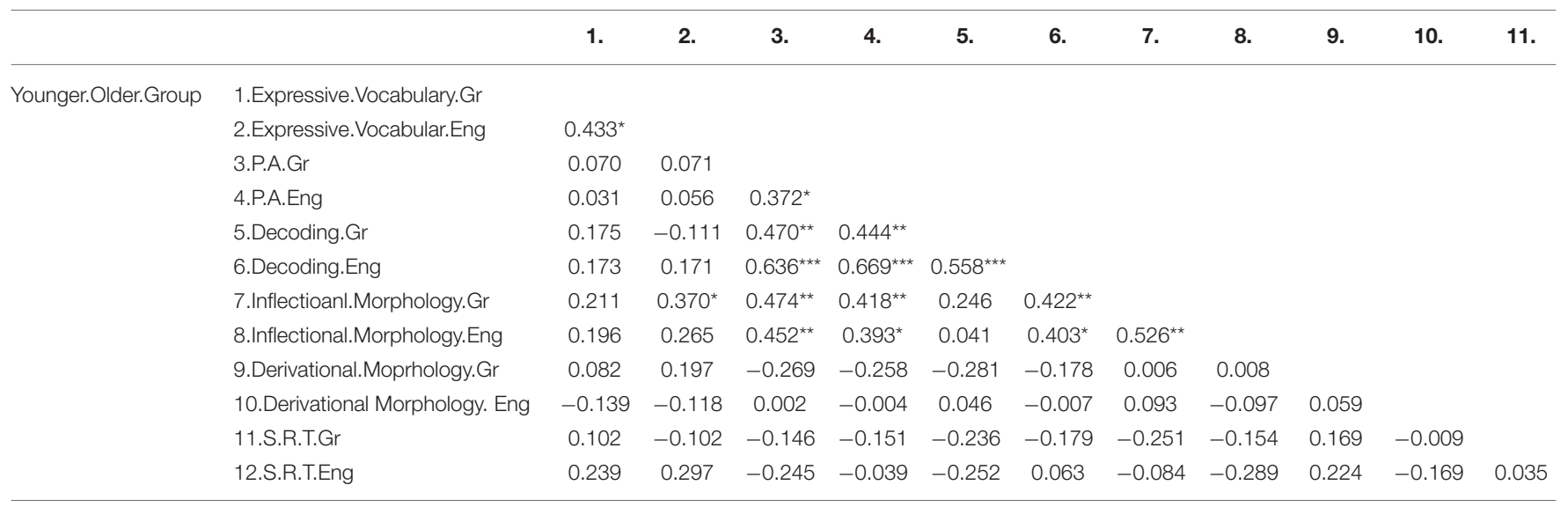

${ }^{* * *}$ Correlation is significant at the 0.001 level (2-tailed).

${ }^{* *}$ Correlation is significant at the 0.01 level (2-tailed).

${ }^{*}$ Correlation is significant at the 0.05 level (2-tailed).

performed better in the English than the Greek tasks in both School Year 1 and 3.

This demonstrates first that the parents were accurate in judging their children's relative language skills in the two languages and suggests that our language history questionnaire was a valid tool for measuring language dominance. Second, the reported switch from dominance in the minority language before school to dominance in the majority language during the school years is in line with previous studies addressing language dominance in children (Cobo-Lewis et al., 2002; Hammer et al., 2008; Sheng, 2014). Indeed, even the children in our sample who were in Year 1 were dominant in English. This could be explained by the fact that our participants were either born in or moved to the UK at least 2 years before their participation in our study and they had attended nursery school including Reception, which in the UK precedes Year 1 and is the first year of formal schooling in the UK. Therefore, given their prior experience of schooling pre-school in the UK, their language dominance had already shifted from Greek to English by the time the current study was conducted.

\section{Associations Between Language and Reading Skills and Contextual Factors}

The study also addressed whether language (expressive vocabulary, phonological awareness, morphological awareness, morpho-syntactic skills) and reading skills (decoding) in Greek and English were associated with contextual factors (language use before the age of 4 years, current language use at home, and outside the home, parental self-rated language proficiency and their educational level).

Focusing first on the Greek language, vocabulary, phonological awareness and morpho-syntax tasks were significantly correlated with language use at home and outside the home. Additionally, performance on decoding was significantly correlated with Greek language use outside the home and parent's educational level.
These findings are in line with several previous studies. For example, Thordardottir (2011) showed that the amount of exposure to a language is significantly related to performance in that language. This relationship is exceptionally strong for expressive vocabulary. In our study, Greek expressive vocabulary was related to the Greek language use in and out the home. However, no significant correlation was found between English expressive vocabulary and English language exposure. This finding is consistent with Duursma et al. (2007), who suggested that English language proficiency did not require parental use of English in the home. However, proficiency in the minority language is dependent upon both support at school and home.

An additional finding was that there was no negative relationship between the use of the minority language and the children's language and word-level reading skills performance in the majority language. In line with the findings from previous studies related to language exposure, the use of the minority language did not impact the children's developing English (majority language) vocabulary and reading skills (GutiérrezClellen and Kreiter, 2003; Duursma et al., 2007; Hammer et al., 2009). For example, Hammer et al. (2009) demonstrated that the use of Spanish in the home did not have an impact on English language and reading skills. On the contrary, the use of Spanish in the home as the minority language could promote children's developing language skills in both the minority and the majority language. This finding has important implications for bilingual families because it demonstrates that supporting the use of heritage languages in the home is not harmful to children's language abilities in the majority language. Moreover, Greek language use in and outside the home was significantly correlated with Greek morphology and morpho-syntactic skills, indicating that parental support of the minority language not only in but also outside the home is important for the maintenance of that language.

In contrast to Chondrogianni and Marinis (2011), we found that the parental English proficiency level was significantly 
correlated with the children's scores in the English morphological awareness tasks. Chondrogianni and Marinis (2011) suggested that the acquisition of morphology may be less sensitive to external factors than the acquisition of vocabulary and complex syntax. However, Chondrogianni and Marinis (2011) finding does not necessarily oppose the present findings. The differences between our study and Chondrogianni and Marinis (2011) findings could be because: a. most of the parents in the study of Chondrogianni and Marinis (2011) had low proficiency in English compared to parental proficiency of our study; b. most of the mothers in Chondrogianni and Marinis (2011) study had $<12$ years of formal education, indicating that the sample was largely representative of low SES compared to our study; c. different tasks were used in order to measure the language skills.

As far as decoding skills are concerned, it is worth noting that there was no significant correlation between the English language and reading skills and the quantity/quality of use of that language in the home and outside the home. This finding could be explained by the fact that the language spoken in U.K. schools is exclusively English. As a result, input and use of English in school is relatively consistent across children and can level out individual differences in exposure to the majority language outside school.

Similar to Dickinson and Porche (2011), our findings showed a significant relationship between vocabulary, decoding skills and language exposure in Greek. Furthermore, our findings revealed that Greek language use outside the home and parental educational level were associated with children's Greek decoding skills. The association with language use could be explained by the fact that parents may tend to promote their mother language taking their children to activities where Greek is spoken. The association of the parental educational level could be due to the fact that parents with higher education levels may devote more time with their children doing home literacy activities. Further research is needed to investigate the relationship between parental educational level and language proficiency and bilingual children's language and reading development.

\section{Cross-Language Associations Between the Greek and English Tasks}

An additional area of interest was to examine cross-language correlations for expressive vocabulary, phonological awareness, morphological awareness, morpho-syntactic skills and decoding skills controlling for age.

Our findings on phonological awareness are in line with Dickinson et al. (2004) who examined various factors that contribute to Spanish-English children's phonological awareness in both of their languages. Dickinson et al. (2004) addressed whether Spanish phonological awareness could be transferred to English and vice versa, and the extent to which children's performance in vocabulary in both languages and emergent literacy in both languages could affect the development of phonological awareness. Their findings showed that the most powerful predictor of phonological awareness in both languages is phonological awareness in the other language. This is in agreement with our results showing significant correlations between all Greek and English phonological awareness tasks.

In terms of morphological awareness, our findings showed that there was a significant correlation between Greek and English morphological awareness tasks. This finding is in contrast with Gutierrez-Clellen et al. (2008) study. The authors investigated the extent to which bilingual children perform different to grammatical tasks due to cross-linguistic effects from their first language. The results demonstrated that there was no evidence of a cross-linguistic effect. This could be because the verb morphologies of two languages in their study (Spanish and English) do not have common core features. Further research with other language pairs (e.g., Italian and Spanish) may shed light on whether cross-linguistic transfer in morphological awareness is more likely to occur in languages with common morphological characteristics.

With regard to decoding, the correlation between English and Greek scores was high. This finding could support the argument that learning a first language with a more transparent orthography could enhance phonological and decoding skills in the second language (Geva and Siegel, 2000). However, this argument should be treated cautiously as comparisons between monolinguals and bilinguals could give us clearer results. Additionally, the high performance on phonological awareness could explain the high performance on decoding tasks. Several studies have supported the argument that phonological awareness is a strong predictor of decoding across the languages (Ziegler et al., 2010; Melby-Lervåg et al., 2012; Gottardo et al., 2016). Indeed, having exposure to a consistent orthography like Greek might be responsible for allowing these children to develop strong phonological awareness and decoding skills in a language with opaque orthography, like English. Many studies have shown that the relationship between phonological awareness and reading is bidirectional (Castles and Coltheart, 2004). Although further research is needed to shed light on the above argument, our research does at least show that exposure to a minority language has certainly no obvious negative effects on the children's reading development in the majority language and may indeed have had a positive effect.

The within and between languages correlations showed that both Greek and English phonological awareness were significantly correlated with Greek and English decoding tasks indicating cross-language relationships. This finding is in agreement with Durgunoglu et al. (1993). The authors revealed that Spanish-English performance in English word and pseudoword tests was predicted by the level of Spanish phonological awareness and word recognition, suggesting crosslanguage transfer. Based on this finding, it is feasible to build on the skills that a child has already gained in his/her first language. Moreover, Durgunoglu et al. (1993) stressed that phonological awareness is not developed specifically in a particular language, but there are similar types of processing underling both Spanish and English. Given that view, children with high metalinguistic awareness in their first language will be able to perform better in their second language. 


\section{CONCLUSION}

Our study aimed to investigate how Greek-English bilingual children who acquire Greek as a minority language and English as a majority language in the first and third year of primary school in the UK perform on several domains relating to both language and decoding dimensions of the Simple View of Reading (Gough and Tunmer, 1986), in both of the bilingual children's languages and how this performance is affected by contextual factors in order to understand more fully the benefits of bilingualism. Additionally, we aimed to investigate cross-language relationships in the children's reading abilities. The broad aim of this research was to understand more fully the benefits of bilingualism through investigating the ways in which developing readers can transfer knowledge from L1 to facilitate L2 learning. In addition to their theoretical relevance, findings may benefit parents and teachers of bilingual children, in enhancing understanding of what to expect in terms of children's language and reading development, and in particularly of the importance and benefits of supporting children's minority as well as majority language. This is one of the few studies investigating effects of language dominance in language and reading abilities in both languages spoken by the children.

The findings confirm that language dominance could change even before children enter school and affects language and literacy skills equally: children have better skills in the majority compared to the minority language in both Year 1 and Year 3. Additionally, we did not find any negative relationship between the use of the heritage language and children's language and reading performance in the majority language (Brunell and Linnakylä, 1994; Duursma et al., 2007; Gutierrez-Clellen et al., 2008). In contrast, significant positive cross-language associations were revealed among vocabulary, phonological

\section{REFERENCES}

Babayigit, S. (2014). The role of oral language skills in reading and listening comprehension of text: a comparison of monolingual (L1) and bilingual (L2) speakers of English language. J. Res. Read. 37, S22-S47. doi: 10.1111/j.1467-9817.2012.01538.x

Bellocchi, S., Tobia, V., and Bonifacci, P. (2017). Predictors of reading and comprehension abilities in bilingual and monolingual children: a longitudinal study on a transparent language. Read. Writ. 30, 1311-1334. doi: 10.1007/s11145-017-9725-5

Bonifacci, P., and Tobia, V. (2017). The simple view of reading in bilingual language-minority children acquiring a highly transparent second language. Sci. Stud. Read. 21, 109-119. doi: 10.1080/10888438.2016.1261869

Bradley, L., and Bryant, P. E. (1983). Categorizing sounds and learning to read-a causal connection. Nature 301, 419. doi: 10.1038/301419a0

Brunell, V., and Linnakylä, P. (1994). Swedish speakers' literacy in the Finnish society. J. Reading 37, 368-375.

Cahill, D. (1987). Bilingual development of Italo-Australian children. Aust. Rev. Appl. Linguist. 4, 101-127. doi: 10.1075/aralss.4.07cah

Caravolas, M., Lervåg, A., Mousikou, P., Efrim, C., Litavský, M., OnochieQuintanilla, E., et al. (2012). Common patterns of prediction of literacy development in different alphabetic orthographies. Psychol. Sci. 23, 678-686. doi: 10.1177/0956797611434536

Casalis, S., and Louis-Alexandre, M.-F. (2000). Morphological analysis, phonological analysis and learning to read French: a longitudinal study. Read. Writ. 12, 303-335. doi: 10.1023/A:1008177205648 awareness, inflectional morphology and decoding skills. A strong relationship between language use and performance was only in evidence in the minority language, which suggests that parental effort should be directed toward the minority language because schooling appears to level out differences in the majority language. The practical implications of this study are that parents and teachers should be informed for the positive effects of heritage language use in and outside the home for the maintenance of the heritage language and for the development of the children's language and literacy skills.

\section{DATA AVAILABILITY STATEMENT}

The datasets generated for this study are available on request to the corresponding author.

\section{ETHICS STATEMENT}

The study has been reviewed by the Research Ethics Committee of the School of Psychology and Clinical Language Sciences at the University of Reading and has been given a favorable ethical opinion for conduct (ethics application number: 2016-217-TM). All investigators on this project have had criminal records checks and have been approved to work with children. Written informed consent to participate in this study was provided by the participants' legal guardian/next of kin.

\section{AUTHOR CONTRIBUTIONS}

The study was conceptualized and designed by all three authors. The data were collected and analyzed by TP under the supervision of TM and DP. The paper was written up by TP, TM, and DP.

Castles, A., and Coltheart, M. (2004). Is there a causal link from phonological awareness to success in learning to read? Cognition 91, 77-111. doi: 10.1016/S0010-0277(03)00164-1

Chiappe, P., Chiappe, D. L., and Gottardo, A. (2004). Vocabulary, context, and speech perception among good and poor readers. Edu. Psychol. 24, 825-843. doi: 10.1080/0144341042000271755

Chiappe, P., Siegel, L. S., and Wade-Woolley, L. (2002). Linguistic diversity and the development of reading skills: a longitudinal study. Sci. Stud. Read. 6, 369-400. doi: 10.1207/S1532799XSSR0604_04

Chitiri, H.-F., and Willows, D. M. (1997). Bilingual word recognition in English and Greek. Appl. Psycholinguist. 18, 139-156. doi: 10.1017/S0142716400009942

Chondrogianni, V., and Marinis, T. (2011). Differential effects of internal and external factors on the development of vocabulary, tense morphology and morpho-syntax in successive bilingual children. Linguist. Approaches Bilingualism 1, 318-345. doi: 10.1075/lab.1.3.05cho

Cobo-Lewis, A. B., Pearson, P. Z., Eilers, R. E., and Umbel, V. C. (2002). "Effects of bilingualism and bilingual education on oral and written Spanish skills: A multifactor study of standardized test outcomes," in Language and Literacy in Bilingual Children, eds D. K. Oller and R. E. Eilers (Clevedon, UK: Multilingual Matters), 98-117.

Cummins, J. (1976). The influence of bilingualism on cognitive growth: synthesis of research findings and explanatory hypotheses. Working Papers Bilingualism $9,1-44$.

Cummins, J. (1979). Linguistic interdependence and the educational development of bilingual children. Rev. Edu. Res. 49, 222-251. doi: $10.3102 / 00346543049002222$ 
Cummins, J. (2004). Multiliteracies Pedagogy and the Role of Identity Texts. Toronto, ON: Ontario Institute for Studies in Education of the University of Toronto and the Elementary Foundation of Teachers of Ontario.

De Houwer, A. (2009). An Introduction to Bilingual Development. Oxford: Multilingual Matters.

de Jong, P. F., and van der Leij, A. (1999). Specific contributions of phonological abilities to early reading acquisition: results from a Dutch latent variable longitudinal study. J. Edu. Psychol. 91:450. doi: 10.1037/0022-0663.91.3.450

Dickinson, D. K., McCabe, A., Clark-Chiarelli, N., and Wolf, A. (2004). Crosslanguage transfer of phonological awareness in low-income Spanish and English bilingual preschool children. Appl. Psycholinguistics 25, 323-347.

Dickinson, D. K., and Porche, M. V. (2011). Relation between language experiences in preschool classrooms and children's kindergarten and fourth-grade language and reading abilities. Child Dev. 82, 870-886. doi: 10.1111/j.1467-8624.2011.01576.x

Dickinson, D. K., and Tabors, P. O. (eds.). (2001). Beginning Literacy with Language: Young Children Learning at Home and School. Baltimore, MD: Paul H Brookes Publishing.

Dolson, D. P. (1985). The effects of Spanish home language use on the scholastic performance of Hispanic pupils. J. Multilingual Multicult. Dev. 6, 135-155. doi: 10.1080/01434632.1985.9994192

Durgunoglu, A. Y., Nagy, W. E., and Hancin-Bhatt, B. J. (1993). Crosslanguage transfer of phonological awareness. J. Edu. Psychol. 85:453. doi: 10.1037/0022-0663.85.3.453

Duursma, E., Romero-Contreras, S., Szuber, A., Proctor, P., Snow, C., August, D., et al. (2007). The role of home literacy and language environment on bilinguals' English and Spanish vocabulary development. Appl. Psycholinguist. 28, 171-190. doi: 10.1017/S0142716406070093

Gathercole, V. C. M., and Thomas, E. M. (2009). Bilingual firstlanguage development: dominant language takeover, threatened minority language take-up. Bilingualism Language Cogn. 12, 213-237. doi: $10.1017 /$ S1366728909004015

Genesee, F. (2006). "Bilingual first language acquisition in perspective," in Childhood Bilingualism: Research on Infancy through School Age, eds M. Peggy and H. Erika (Clevedon: Multilingual Matters Ltd.), 45-67. doi: $10.21832 / 9781853598715-005$

Georgiou, G., Parrila, R., and Papadopoulos, T. (2008). Predictors of word decoding and reading fluency across languages varying in orthographic consistency. J. Edu. Psychol. 100:566. doi: 10.1037/0022-0663.100.3.566

Georgiou, G. K., Papadopoulos, T. C., Zarouna, E., and Parrila, R. (2012). Are auditory and visual processing deficits related to developmental dyslexia? Dyslexia 18, 110-129. doi: 10.1002/dys.1439

Geva, E., and Siegel, L. S. (2000). Orthographic and cognitive factors in the concurrent development of basic reading skills in two languages. Read. Writ. 12, 1-30. doi: 10.1023/A:1008017710115

Geva, E., and Wang, M. (2001). The development of basic reading skills in children: a cross-language perspective. Ann. Rev. Appl. Linguistics 21, 182-204. doi: 10.1017/S0267190501000113

Geva, E., Yaghoub-Zadeh, Z., and Schuster, B. (2000). Understanding individual differences in word recognition skills of ESL children. Ann. Dyslexia 50, 121-154. doi: 10.1007/s11881-000-0020-8

Gottardo, A., Pasquarella, A., Chen, X., and Ramirez, G. (2016). The impact of language on the relationships between phonological awareness and word reading in different orthographies: a test of the psycholinguistic grain size theory in bilinguals. Appl. Psycholinguist. 37, 1083-1115. doi: $10.1017 /$ S0142716415000508

Gough, P. B., and Tunmer, W. E. (1986). Decoding, reading, and reading disability. Remedial Special Edu. 7, 6-10. doi: 10.1177/074193258600700104

Gutiérrez-Clellen, V. F., and Kreiter, J. (2003). Understanding child bilingual acquisition using parent and teacher reports. Appl. Psycholinguistics 24, 267-288.

Gutierrez-Clellen, V. F., Simon-Cereijido, G., and Wagner, C. (2008). Bilingual children with language impairment: A comparison with monolinguals and second language learners. Appl. Psycholinguistics 29, 3-19. doi: $10.1017 / \mathrm{s} 0142716408080016$

Hammer, C. S., Davison, M. D., Lawrence, F. R., and Miccio, A. W. (2009). The effect of maternal language on bilingual children's vocabulary and emergent literacy development during Head Start and kindergarten. Sci. Stud. Reading $13,99-121$

Hammer, C. S., Lawrence, F. R., and Miccio, A. W. (2008). Exposure to English before and after entry into head start: bilingual children's receptive language growth in Spanish and English. Int. J. Bilingual Educ. Bilingualism 11, 30-56. doi: $10.2167 /$ beb376.0

Hoff, E., Core, C., Place, S., Rumiche, R., Señor, M., and Parra, M. (2012). Dual language exposure and early bilingual development. J. Child Language 39, 1-27. doi: $10.1017 /$ S0305000910000759

Kirby, J. R., A., D., Roth, L., and Lai, S. S. (2008). Longitudinal predictors of word reading development. Can. Psychol. 49:103. doi: 10.1037/0708-5591.49.2.103

Lindsey, K. A., Manis, F. R., and Bailey, C. E. (2003). Prediction of first-grade reading in Spanish-speaking English-language learners. J. Edu. Psychol. 95:482. doi: $10.1037 / 0022-0663.95 .3 .482$

Marchman, V. A., Fernald, A., and Hurtado, N. (2010). How vocabulary size in two languages relates to efficiency in spoken word recognition by young Spanish-English bilinguals. J. Child Language 37, 817-840. doi: 10.1017/S0305000909990055

Marinis, T., and Armon-Lotem, S. (2014). "Sentence repetition," in Assessing Multilingual Children: Disentangling Bilingualism from Language Impairment, eds S. Armon-Lotem, N. Meir, and J. de Jong (Clevendon, UK: Multilingual Matters), 116-143. doi: 10.21832/9781783093137-007

Melby-Lervåg, M., and Lervåg, A. (2011). Cross-linguistic transfer of oral language, decoding, phonological awareness and reading comprehension: a meta-analysis of the correlational evidence. J. Res. Read. 34, 114-135. doi: 10.1111/j.1467-9817.2010.01477.x

Melby-Lervåg, M., Lyster, S.-A. H., and Hulme, C. (2012). Phonological skills and their role in learning to read: a meta-analytic review. Psychol. Bull. 138:322. doi: $10.1037 / \mathrm{a} 0026744$

Montrul, S. (2008). Incomplete Acquisition in Bilingualism: Re-examining the Age Factor. Amsterdam: John Benjamins.

Montrul, S. (2016). "Dominance and proficiency in early and late bilingualism," in Language Dominance in Bilinguals: Issues of Measurement and Operationalization, eds C. Silva-Corvalán and J. Treffers-Daller (Cambridge: Cambridge University Press), 5-35. doi: 10.1017/CBO9781107375345.002

Muter, V., Hulme, C., Snowling, M. J., and Stevenson, J. (2004). Phonemes, rimes, vocabulary, and grammatical skills as foundations of early reading development: evidence from a longitudinal study. Dev. Psychol. 40:665. doi: $10.1037 / 0012-1649.40 .5 .665$

Nation, K., and Snowling, M. J. (2004). Beyond phonological skills: broader language skills contribute to the development of reading. J. Res. Read. 27, 342-356. doi: 10.1111/j.1467-9817.2004.00238.x

Nunes, T., Bryant, P., and Bindman, M. (1997). Morphological spelling strategies: developmental stages and processes. Dev. Psychol. 33:637. doi: $10.1037 / 0012-1649.33 .4 .637$

Ouellette, G. P. (2006). What's meaning got to do with it: the role of vocabulary in word reading and reading comprehension. J. Edu. Psychol. 98:554. doi: $10.1037 / 0022-0663.98 .3 .554$

Ouellette, G. P., and Beers, A. (2010). A not-so-simple view of reading: how oral vocabulary and visual-word recognition complicate the story. Read. Writ. 23, 189-208. doi: 10.1007/s11145-008-9159-1

Pearson, B. Z., Fernandez, S. C., Lewedeg, V., and Oller, D. K. (1997). The relation of input factors to lexical learning by bilingual infants. Appl. Psycholinguist. 18, 41-58. doi: 10.1017/S0142716400009863

Pittas, E., and Nunes, T. (2014). The relation between morphological awareness and reading and spelling in Greek: a longitudinal study. Read. Writ. 27, 1507-1527. doi: 10.1007/s11145-014-9503-6

Raven, J., Raven, J. C., and Court, J. H. (2004). Manual for Raven's Progressive Matrices and Vocabulary Scales. Section 3: The Standard Progressive Matrices.

Renfrew, C. (1995). Word Finding Vocabulary Test, 4th Edn. Bicester: Speechmark Publishing.

Ricketts, J., Nation, K., and Bishop, D. V. (2007). Vocabulary is important for some, but not all reading skills. Sci. Stud. Read. 11, 235-257. doi: 10.1080/10888430701344306

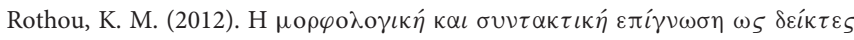

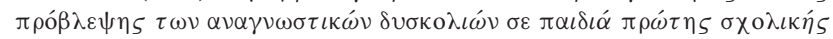
$\eta \lambda \iota \kappa i \alpha \varsigma .(\mathrm{PhD})$. П $\alpha \nu \varepsilon \pi \iota \sigma \tau \eta \dot{\mu} \mu \iota \Theta \varepsilon \sigma \sigma \alpha \lambda i \alpha \varsigma$ 
Scarborough, H. S. (1998). "Early identification of children at risk for reading disabilities: Phonological awareness and some other promising predictors," in Specific Reading Disability: A View of the Spectrum, eds B. K. Shapiro, P. J. Accardo, and A. J. Capute (Timonium, MD: York Press), 75-119.

Seymour, P. H., Aro, M., Erskine, J. M., and network, C. A. A. (2003). Foundation literacy acquisition in European orthographies. Br. J. Psychol. 94, 143-174. doi: $10.1348 / 000712603321661859$

Sheng, L. (2014). Lexical-semantic skills in bilingual children who are becoming English-dominant: A longitudinal study. Bilingualism: Lang. Cogn. 17, 556-571. doi: $10.1017 /$ S1366728913000746

Silva-Corvalán, C., and Treffers-Daller, J. (Eds.). (2015). Language Dominance in Bilinguals: Issues of Measurement and Operationalization. Cambridge: Cambridge University Press.

Smythe, I., Everatt, J., Al-Menaye, N., He, X., Capellini, S., Gyarmathy, E., et al. (2008). Predictors of word-level literacy amongst Grade 3 children in five diverse languages. Dyslexia 14, 170-187. doi: 10.1002/dys.369

Suggate, S., Reese, E., Lenhard, W., and Schneider, W. (2014). The relative contributions of vocabulary, decoding, and phonemic awareness to word reading in English versus German. Read. Writ. 27, 1395-1412. doi: $10.1007 / \mathrm{s} 11145-014-9498-\mathrm{z}$

Thordardottir, E. (2011). The relationship between bilingual exposure and vocabulary development. Int. J. Bilingualism 15, 426-445. doi: $10.1177 / 1367006911403202$

Thordardottir, E., Rothenberg, A., Rivard, M.-E., and Naves, R. (2006). Bilingual assessment: can overall proficiency be estimated from separate measurement of two languages? J. Multilingual Commun. Disord. 4, 1-21.

Torgesen, J. K., Rashotte, C. A., and Wagner, R. K. (1999). TOWRE: Test of word reading efficiency. Toronto, ON: Psychological Corporation.

Torgesen, J. K., Wagner, R., and Rashotte, C. (2012). Test of Word Reading Efficiency:(TOWRE-2). Austin, TX: Pearson Clinical Assessment.

Tuller, L. (2015). 11 clinical use of parental questionnaires in multilingual contexts. Assess. Multilingual Children 13:301. doi: 10.21832/9781783093137-013
Verhoeven, L. (2000). Components in early second language reading and spelling. Sci. Stud. Read. 4, 313-330. doi: 10.1207/S1532799XSSR0404_4

Verhoeven, L., van Leeuwe, J., and Vermeer, A. (2011). Vocabulary growth and reading development across the elementary school years. Sci. Stud. Read. 15, 8-25. doi: 10.1080/10888438.2011.536125

Vogindroukas, I., Protopapas, A., and Sideridis, G. (2009). Test of Expressive Vocabulary. Chania: Glafki.

Wagner, R., Torgesen, J., and Rashotte, C. (1994). Development of readingrelated phonological processing abilities: new evidence of bidirectional causality from a latent variable longitudinal study. Dev. Psychol. 30:73. doi: 10.1037/0012-1649.30.1.73

Wagner, R., Torgesen, J., Rashotte, C., and Pearson, N. (2013). Comprehensive Test of Phonological Processing-2nd ed (CTOPP-2). Austin: Pro-Ed.

Ziegler, J. C., and Goswami, U. (2005). Reading acquisition, developmental dyslexia, and skilled reading across languages: a psycholinguistic grain size theory. Psychol. Bull. 131:3. doi: 10.1037/0033-2909.131.1.3

Ziegler, J. C., Pech-Georgel, C., Dufau, S., and Grainger, J. (2010). Rapid processing of letters, digits and symbols: what purely visualattentional deficit in developmental dyslexia? Dev. Sci. 13, F8-F14. doi: 10.1111/j.1467-7687.2010.00983.x

Conflict of Interest: The authors declare that the research was conducted in the absence of any commercial or financial relationships that could be construed as a potential conflict of interest.

Copyright (c) 2019 Papastefanou, Powell and Marinis. This is an open-access article distributed under the terms of the Creative Commons Attribution License (CC BY). The use, distribution or reproduction in other forums is permitted, provided the original author(s) and the copyright owner(s) are credited and that the original publication in this journal is cited, in accordance with accepted academic practice. No use, distribution or reproduction is permitted which does not comply with these terms. 